\title{
Exchange of Rural Residential Land in China
}

\author{
Wen Yan \\ College of Business, Agricultural University of Hebei \\ Baoding 071000, Hebei, China \\ E-mail: yanwen17@gmail.com \\ Yueming $\mathrm{Xu}$ \\ College of Business, Agricultural University of Hebei \\ Baoding 071000, Hebei, China \\ E-mail: xymbd@126.com
}

\begin{abstract}
China's economy is experiencing rapid urbanization, which is featured by both inefficient rural residential land and insufficient urban construction land. Another characteristic of China's urbanization is the frequent phenomenon of "over-urbanization" in developing countries. Population cannot be urbanized as quickly as land, mainly because migrants moving out of rural areas have no affordability of the urban housing. The purpose of this paper is to establish a framework of coordinating urban construction land and rural residential land, changing the inefficient rural residential land into arable land and as the same time increasing the quota of urban construction land, which can both help to improve the supply of urban construction land and help to meet migrants' residential needs in urban areas.
\end{abstract}

Keywords: Rural residential land, Construction land, Land use

\section{Introduction}

\subsection{The Urbanization in China}

It is believed by many experts that the urbanization process follows an "S" shape (Northam, 1975; Davis and Golden, 1954; Graves and Sexton, 1979). Northam even came to the conclusion in his book Urban Geography that urbanization generally goes through three stages, namely, gradual growth, explosive taking off, and maturity (Northam, 1975). In the first stage, the urban population experiences a gradual growth after it accounts for $10 \%$ of the total population. After this proportion being 30\%, urbanization process accelerates until urban population reaches $70 \%$, which is called the second stage. This is followed by the third stage, where the urban population stops growing or even starts decreasing. In 2008, urban population in China was $45.7 \%$ of the total population (National Bureau of Statistics, 2009). Considering the fact that the correlation between China's urbanization and per capita GDP growth has been the same as that of numerous other countries in history (Feng, 2006), China is in the second stage of urbanization process, which can also be proven by the increasing number of migrants moving from rural areas to urban areas. This demographic change has become the most significant feature in Chinese society. However, urbanization in China has some different characteristics than the western world. In western countries, urbanization is propelled by industrialization, which drives labors, capitals, technologies, land and other means of production to flow into urban areas. In China, on the other hand, urbanization is far beyond the industrialization, which is called "over-urbanization" (Marshall, 1998). This "over-urbanization" is supposed to have come about because rural migrants have been pushed rather than "pulled" into the urban areas (Sovani, 1964). Because of low industrialization level, urban employment capacity cannot satisfy the need of rural migrants; when more and more rural cultivated land is transformed into urban construction land, a new group of "land-lost" farmers have emerged. In rural China where there is hardly any pension system and housing guarantee, "land-lost" farmers have lost their housing guarantee and old-age living guarantee when they have lost their land. The housing problem of land-lost farmers has to be solved by urban housing guarantee system. Again, because of low industrialization level, farmers who have lost their land due to urbanization cannot find jobs in urban areas, making migrants' housing in urban areas even more difficult.

China is a typical dual-economy state, characterized by big income disparities between agricultural and urban jobs (both long-term and temporary). This has led to a vast transfer of the labor force from low to high wage 
sectors because of low productivity and low incomes in agriculture, as well as much better living conditions in urban areas. According to "National Economic and Social Development Statistics Report 2009" issued by the National Bureau of Statistics, by the end of 2009, the country's total population was 1.33474 billion and the total urban population was 621.86 million.(NBSA, 2009). Urbanization rate reached $46.6 \%$. Based on the prediction of Association of Mayors' "Report of the Development of Chinese Cities 2001-2002", the development goals of China's urbanization rate around 2050 will be more than $75 \%$ and the urban population correspondingly will be 1.2 billion. It is in about another 40 years that the number of urban population will increase by 578 million, an average annual increase of 14.45 million people.

\subsection{Urbanization's Impacts on Construction Land}

The rapid urbanization in China has impacts on both rural construction land and urban construction land in terms of land use efficiency. First, urbanization has brought in expansion of cities and land use scale; more urban construction sites are in urgent need for land. Whereas, currently, the gap between the quota supplies of urban construction land is far less than the actual demand. Urban construction land, especially the real estate market, has been artificially distorted in terms of price. Besides, the per capita cultivated land in China is very low, only $1.40 \mathrm{mu}\left(933.3 \mathrm{~m}^{2}\right)$ in 2005 , which imposes high pressure on food safety (Zeng, 2005). Therefore, the insufficient urban construction land cannot be supplied by cultivated land. It has to be supplied by rural construction land. Second, urbanization has resulted in low efficiency or even idling of rural construction land (the main part is rural residential land) left by rural migrants. In rural China, households are entitled to certain residential land quota based on their demographic features. With the land quota, rural households can build their own houses without paying for the rent. Legally obtained residential land quota won't be withdrawn during the quota holder's life. When quota holders moves to cities, their still have the right to their land. That migrants flock into urban areas has left their rural residential land empty or only the elder and children. In the countryside, "hollow villages" (kongxin cun) - villages with underutilized land - have become increasingly common (Li, 2007). Rural construction land has not been utilized in an efficient way.

\section{Theoretical Analysis on the Necessity of Coordinating Urban Construction Land and Rural Residential Land}

Urbanization has made the urban construction land the scarcest resource in the economy, whereas in the rural areas, more farmers are moving out of rural areas and looking for jobs in cities, leaving their residential land (the main body of rural construction land) idle and wasted. It can be observed that there is a huge difference in the efficiency of urban construction land and rural construction land. Only by coordinating urban construction land and rural residential land can we stop the rural construction land being wasted, help to meet the urgent need that urbanization has put on urban construction land, balance the huge difference in land use efficiency, and improve the overall efficiency of the land.

Based on article 10 of the "State Council's Decisions on Deepening Reform and Tightening Land Management", "Rural construction land arrangement and consolidation should be encouraged; increasing urban construction land and reducing rural construction land should be hooked up in one arrangement." It is called "Hooking-up Policy". Under this policy, the problem is how to hook up the inefficient rural construction land and the insufficient urban construction land. One approach is to rearrange the quota of the two types of construction land. Theoretically, a healthy urbanization process requires all kinds of production factors flow in a free way. Land quota exchange is the prerequisite of the free flow of "land" as a production factor. Production factors have an innate feature of "flowing to the high efficient activity". Land, as an important production factor, when used inefficiently, will be driven to high efficient activities. In reality, the "flowing to the high efficient activities" of land has been realized by lots of underground transactions of "rural residential land and its quota". Coordinating urban and rural construction land by exchanging residential land quota can release the intrinsic motive force of the underground transaction, and supply to urban construction land in a legal way.

Exchange of farmers' residential land can also help the rural migrants (in China, they are called peasant-workers.) with their housing problems. The settlement of rural migrants in urban areas depends on two factors. One is a stability of urban jobs, the other is the affordability of urban housing, and the latter has become the main obstacle for migrants to settle down in cities. The housing-price-to-income ratio (the ratio of the median market home price to the median annual household income) is very high in China, especially in big cities. Compared to the high housing price, peasant-workers' income is quite low. Moreover, the high mobility of the peasant-farmers makes the Housing Provident Fund System, which is contributed by employers and their staff in return for cut-rate mortgages, based on relatively stable jobs, impossible to function. Therefore, housing problem of peasant-farmers has to be solved by a system in which the farmers have the resource and rights (such as 
residential land) in the first place.

\section{Arrangement of Exchange of Farmers' Residential Land}

\subsection{The Quitting and Exchanging of Farmers' Residential Land}

Due to the location fixity of land, coordinating rural and urban construction land has to be proceeded by construction land quota. It is actually coordinating rural and urban construction land quota. This arrangement can be summarized as "Quitting and Exchanging", which involves three aspects (Figure 1):

(1) A farmer (for example farmer "A") quits one's quota of rural residential land via returning the quota back to the Land and Resources Management Department at township level, and receives a certificate called "Residential Land Quitting Certificate", by which farmer A can get the "Urban Housing Privilege Certificate"--the right to a certain amount of urban housing according to the amount of residential land he/she has quit or the right to buy houses at a favorable price in a certain urban area (for example City X).

(2) That urban area (City X) can be reimbursed with the same amount of land quota farmer A has quit, for urban construction.

(3) Rural residential land that farmer A has quit is reclaimed to cultivated land.

\section{Insert Figure 1 Here}

Three principals should be followed. (1) This arrangement is on a voluntary based. (2) Because of the social welfare nature of this arrangement, the certificate cannot be circulated in market. (3) For the purpose of cultivated land protection and food safety, the residential land that can be quit must be reclamationable. (4) Considering the particularity of the real estate market, the right to exchange a certain amount of housing by quitting one's residential land shall be imposed an "exercise period", which is no longer than 5 years, in case of inflation of the certificate's price.

\subsection{Administration of "Quitting and Exchanging" Arrangement}

This arrangement involves Land and Resources Management Departments at both township level and municipal level, Government Finance Departments at municipal level, and Housing and Property Management sectors at municipal level. Responsibilities of Land and Resources Management Departments at township level include: to process farmers' applications of quitting residential land, to review if the residential land is qualified to be quit, to issue the "Residential Land Quitting Certificate", to process the registry and filing of the quit residential land, to administrate and supervise the reclamation of the residential land, and to investigate the reclamation process. Responsibilities of Finance Departments at township level include: to set up a special account to cover the expense of purchases of the "Residential Land Quitting Certificate" and to collect the income from selling the quota of construction land supplied by farmers who exert their "exchanging right". Responsibilities of Land and Resources Management Departments at municipal level include: to review the application of exchanging "Residential Land Quitting Certificate", to calculate the urban construction land quota exchanged from the rural construction land quit and reclaimed, to calculate the housing size a farmer can exchange with one's certificate, to issue the "Urban Housing Privilege Certificate" to farmers, with which, farmers can exchange certain size of urban housing or make the purchase at a favorable price.

Farmers who have "Urban Housing Privilege Certificate" make their applications to the Housing and Property Management sector of the municipal government. Housing and Property Management sector is in charge of reviewing the "Urban Housing Privilege Certificate" and issue urban housing to farmers.

\section{Conclusion}

Rapid urbanization results in urgent need for urban construction land and the idling of rural construction land, also brings the need for land management policies to improve the efficiency and rationality of land use in both urban areas and rural areas in China. Exchange of rural residential land quota can coordinate urban construction land and rural residential land. Farmers by selling their residential land quota can get certain amount of urban housing. Also the residential land can be reclaimed into cultivated land; the urban construction land can be supplied. It is an arrangement which will make the urbanization proceed in an economically efficient, socially just and environmentally sustainable manner.

\section{References}

Davis, K. and H. Golden. (1954). Urbanization and the Development of Pre-Industrial Areas. Economic Development and Cultural Change. 3, 6-26.

Feng, Junxin \& David D. Li. (2006). Stages of Urbanization: Is China's Urbanization Poised to Take Off? 
Working Paper. Of Hong Kong University of Science and Technology. [Online] Available: http://www.ccwe.org.cn/ccweold/papers/workingpaper/working_paper--Stagees_of_Urbanization_060924.pdf

(Dec. 11, 2009).

Graves P. and R. Sexton. (1979). Overurbanization and Its Relation to Economic Growth for Less Developed Countries. Economic Forum. 8(1), 95-100.

Li, Meihua. (2009). The Role of Grassroots' Officials on Hollow Village management. Rural Economy. 9, 124-126.

Marshall, Gordon. (1998). "Over-Urbanization” A Dictionary of Sociology. [Online] Available: http://www.encyclopedia.com/doc/1O88-overurbanization.html (Dec. 7, 2009).

National Bureau of Statistics of China (NBSA). (2009). Statistical Communiqué on the 2009 National Economic and Social Development.

National Bureau of Statistics. (2009). Statistical Communiqué on the 2008 National Economic and Social Development.
[Online] http://www.stats.gov.cn/english/newsandcomingevents/t20090226_402540784.htm (Dec. 11, 2010).

Northam, R. M. (1975). Urban Geography. New York: John Wiley \& Sons.

Sovani, N.V. (1964). The Analysis of "Over-Urbanization". Economic Development and Cultural Change. XII (2).

Zeng, Xianming. (2005). A Study of the Road to Urbanization with China's Characteristics. Doctoral Dissertation of Wuhan University.

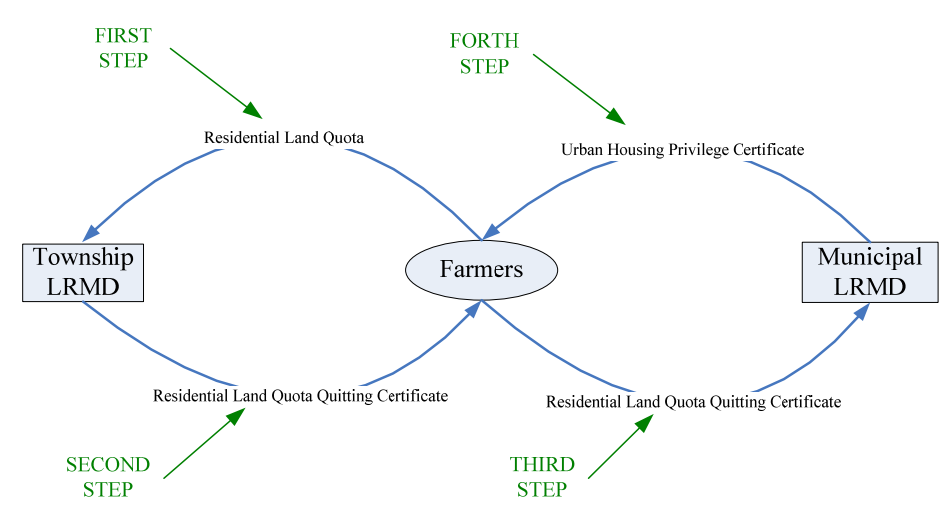

Figure 1. Process of Exchange of Farmers' Residential Land 